\title{
A Comparison of Patient Safety Competencies between Clinical and Classroom Settings among Nursing Students
}

\author{
Rizqi Amilia ${ }^{1}$, Devi Nurmalia ${ }^{2}$ \\ ${ }^{1}$ Student of Department of Nursing, Faculty of Medicine, Universitas Diponegoro, Indonesia \\ ${ }^{2}$ Department of Nursing, Faculty of Medicine, Universitas Diponegoro, Indonesia \\ Corresponding Author: Devi Nurmalia (devinurmalia@lecturer.undip.ac.id)
}

\begin{abstract}
Background: As nurses play an important role in the implementation of patient safety in hospitals, competencies of patient safety should be developed and enhanced among nursing students. Self-assessment is a method that can be used to assess patient safety and its dimensions to help the students prepare themselves before entering the work life. Purpose: This study aimed to investigate differences in patient safety competencies between the classroom and clinical settings among nursing students using a selfassessment method.

Methods: A descriptive study using the Health Professional Education in Patient Safety Survey (H-PEPSS) questionnaire was conducted among 181 nursing students in a public university in Indonesia. Paired t-test, ANOVA, and independent t-test were performed to determine the comparison in the values of patient safety dimensions across the classroom, clinical learning, and year of nursing course.

Results: Nursing students showed a higher mean value in the classroom setting than in the clinical setting. Out of the seven dimensions of patient safety competencies, "clinical safety" $(M=4.36)$ and "communicate effectively" $(M=4.29)$ obtained the highest score in the classroom setting, while "adverse events" showed the lowest $(M=4.03)$. In the clinical setting, "clinical safety" $(M=4.19)$ and "communicate effectively" $(M=4.12)$ obtained the highest score, while "working in teams" $(M=3.82)$ was the lowest. The third-year students showed a better score than the fourth year in most dimensions.

Conclusion: In this study, the patient safety competencies among nursing students were higher in the classroom setting than in the clinical setting. It is recommended to investigate the factors that can increase the achievement of patient safety competence among nursing students in the clinical setting.
\end{abstract}

Keywords: Patient safety competences; self-assessment; nursing students

How to Cite: Amilia, R., \& Nurmalia, D. (2020). A comparison of patient safety competencies between clinical and classroom settings among nursing students. Nurse Media Journal of Nursing, 10(1), 66-75. doi:10.14710/nmjn.v10i1.25231

Permalink/DOI: https://doi.org/10.14710/nmjn.v10i1.25231 


\section{BACKGROUND}

Patient safety is a significant health issue to discuss. It is an essential requirement in the assessment of hospital accreditation nowadays. The Joint Commission International (JCI) employs patient safety as one of the hospital's international standards (The Joint Commission, 2018). In addition to accreditation regulations, increased awareness of patient safety is also applied by the World Health Organization to service providers as well as health professional education institutions with the presence of a Patient Safety Curriculum Guide (Usher et al., 2017; World Health Organization, 2011). The effort is made to provide safe health services for patients.

Nurses, as a part of health workers, have an essential role in the implementation of patient safety. Nurses are the most significant number of health workers so that their roles in identifying, deciding, and correcting medical errors are significant (Attree, Cooke, \& Wakefield, 2008; da Costa, Santos, Junior, Vitor, de Oliveira Salvador, \& Alves, 2017; Kim, Jeong, \& Kwon, 2018; Lukewich et al., 2015). A large number of nurses also has direct implications on patient safety and error prevention strategies (da Costa et al., 2017). Therefore, nurses are required to carry out the care that is safe for patients. Due to the importance of implementing safety measures, patient safety education is required to be organized for all health workers.

Education plays an important role in the efforts made to implement patient safety. As a result, the health departments are triggered to collaborate with educational institutions in the delivery of patient safety education (da Costa et al., 2017; Steven, Magnusson, Smith, \& Pearson, 2014). This collaboration is carried out as a preventive effort since students who undertake clinical education will also provide services to patients. One of the ways for educational institutions to improve the quality of the implementation of patient safety is to develop competencies among the students. Competence is important to learn and develop as students have not been fully exposed to patient safety behavior (da Costa et al., 2017; Mansour, 2015; Tella, Liukka, Jamookeeah, Smith, Partanen, \& Turunen, 2013).

Delivering patient safety competencies in the classroom is very important for student nurses, especially for the application in the practice area. Education in the classroom will have a significant impact on behavior that will arise in the realm of the clinic (Colet, Cruz, Otaibi, \& Qubeilat, 2015; Mansour, 2015; Mansour, Skull, \& Parker, 2015; Usher et al., 2017). Education provides not only theoretical knowledge but also awareness related to actual practice areas (Pearson \& Steven, 2009). One of the patient safety competencies in health professional education is the Canadian Patient Safety Institute (CPSI) framework (CPSI, 2009). The points in patient safety competencies are taught in health education institutions in Indonesia. Patient safety competencies need to be assessed even though they are not used as a graduation requirement.

One way to assess an individual's competence is by using the self-assessment method. Self-assessment can be useful as a way of identifying strengths and weaknesses to achieve desired goals (Eva \& Regehr, 2005; Wolff, Santen, Hopson, Hemphill, \& Farrell, 2017). Identification of strengths can lead to a sense of confidence to carry out tasks and plannings without obstacles and doubts. Meanwhile, identification of 
deficiencies can help balance abilities and find ways to overcome deficiencies (Kajander-Unkuri et al., 2014; Stan \& Manea, 2015; Usher et al., 2018; Wolff et al., 2017). Self-perception is affected by many things; one of them is a long time studying. Research shows that the period of study in the classroom and clinical settings affect the implementation of patient safety competence. A previous study showed that third-year students have better self-perception of managing safety risks than the second-year ones (Usher et al., 2017). Another study reported a different finding that lower year students have better self-perceptions than higher year students regarding patient safety competence (Lukewich et al., 2015).

Studies related to patient safety competence in Indonesia are rarely found. A few studies investigated patient safety performance in general and not specific in the classroom or clinical settings (Sari, 2015). A study investigating all aspects of patient safety competencies (Julianto, Thiangchanya, \& Boonyoung, 2014), as similar to the present study, was conducted among hospital nurses, not students. Therefore, this study is important to provide baseline data for informing and evaluating patient safety competence concepts among nursing students in the classroom and clinical settings.

\section{PURPOSE}

The purpose of this study was to investigate the differences in patient safety competencies between the classroom and clinical settings among nursing students.

\section{METHODS}

\section{Design and samples}

This study used a descriptive method with an online survey. The samples were nursing students at the undergraduate program and professional program in a public university in Indonesia who had undertaken clinical practices in the hospital for at least six months and agreed to participate. The total samples were 181 students, consisting of 63 thirdyear students, 69 fourth-year students, and 49 professional nursing students. Stratified random sampling was used to select the samples.

\section{Ethical consideration}

This study was approved by the research ethics committee from the Faculty of Medicine Diponegoro University and Dr. Kariadi Hospital (No. 538/EC/FK-RSDK/VII/2018).

\section{Instrument and data collection}

Data were collected using Google forms that were distributed to the students by the assistance of students' peer coordinators. The first page on the online form contained information regarding the objectives and benefits of the study, as well as informed consent and procedures on how to fill out the questionnaire.

This study used the 2012 version of the Health Professional Education in Patient Safety Survey (H-PEPSS) developed by Dr. Liane Ginsburg from Canada. This instrument was designed as a self-assessment tool to find out knowledge and self-assessment related to six socio-cultural aspects of patient safety in classroom and clinical learning. The domain includes working in teams (6 questions), communicating effectively (3 questions), management of safety risks (3 questions), human and environmental 
understanding (3 questions), adverse events (4 questions), and culture of safety (4 questions). In addition to these six domains, there is another domain, clinical safety, which is a depiction of the daily clinical activities undertaken. Questions were assessed using a Likert scale from 1 (strongly disagree) to 5 (strongly agree). This instrument was chosen because of its wide scope in the healthcare profession for those who have just graduated, nearing completion of the professional education process, or undergraduate students (Usher et al., 2017).

This instrument is originally in English. A back-to-back translation was conducted from English to Indonesian, and vice versa. The Cronbach's alpha scores showed 0.81 for classroom learning and 0.85 for clinical learning (Ginsburg, Castel, Tregunno, \& Norton, 2012). In 2017, Usher tested the questionnaire and obtained higher scores than the original value of 0.885 for classroom learning and 0.892 for clinical learning (Usher et al., 2017). Other questions in the questionnaire asked about demographic data which include gender, age, and year of the study. The completion of the questionnaire took 1015 minutes.

\section{Data analysis}

Statistical analysis was performed using SPSS with $p<0.05$ as a significant value. Demographic data were processed using descriptive statistical analysis. In addition, the differences between study years and patient safety dimensions were analyzed using the paired t-test, ANOVA test, and independent t-test.

\section{RESULTS}

\section{Characteristics of respondents}

The number of respondents who completed the questionnaire was 181 in total. A majority of them were fourth-year students $(38.1 \%)$ and females $(91.2 \%)$ (Table 1$)$.

Table 1. Characteristics of respondents

\begin{tabular}{lllr}
\hline No & Students' characteristics & $f$ & $\%$ \\
\hline 1 & Student group: & & \\
& Professional program students & 49 & 27.1 \\
& 4 $^{\text {th }}$-year students (2014) & 69 & 38.1 \\
& $3^{\text {rd }- \text {-year students (2015) }}$ & 63 & 34.8 \\
\hline 2 & Gender & & \\
& Female & 165 & 91.2 \\
& Male & 16 & 8.8 \\
\hline
\end{tabular}

\section{Dimensions of patient safety in the classroom and clinical learning}

Table 2 shows that students have different scores of patient safety domains in the classroom setting and the clinical setting for most domains. The results were significant except for human and environmental factors and adverse events. The highest two mean scores in the classroom and clinical setting were clinical safety and communicate effectively. Besides, the lowest score, both in the classroom and clinical learning, was the adverse events. 
Table 2. The comparison of the score in the classroom-clinical learning

\begin{tabular}{|c|c|c|c|c|c|}
\hline Patient safety domain & Setting & $N$ & $M$ & $S D$ & $p$-value \\
\hline \multirow[t]{2}{*}{ Clinical safety } & Class & 132 & 4.36 & 0.60 & \multirow[t]{2}{*}{$0.002 *$} \\
\hline & Clinic & 181 & 4.19 & 0.69 & \\
\hline \multirow[t]{2}{*}{ Working in teams } & Class & 132 & 4.06 & 0.58 & \multirow[t]{2}{*}{$0.000^{*}$} \\
\hline & Clinic & 181 & 3.82 & 0.70 & \\
\hline \multirow[t]{2}{*}{ Communicating } & Class & 132 & 4.29 & 0.51 & \multirow[t]{2}{*}{$0.000 *$} \\
\hline & Clinic & 181 & 4.12 & 0.65 & \\
\hline \multirow[t]{2}{*}{ Managing safety risks } & Class & 132 & 4.08 & 0.59 & \multirow[t]{2}{*}{$0.010 *$} \\
\hline & Clinic & 181 & 3.97 & 0.63 & \\
\hline \multirow{2}{*}{$\begin{array}{l}\text { Human and } \\
\text { environmental }\end{array}$} & Class & 132 & 4.08 & 0.62 & \multirow[t]{2}{*}{0.173} \\
\hline & Clinic & 181 & 4.01 & 0.69 & \\
\hline \multirow[t]{2}{*}{ Adverse events } & Class & 132 & 4.03 & 0.56 & \multirow[t]{2}{*}{$0.003^{*}$} \\
\hline & Clinic & 181 & 3.87 & 0.65 & \\
\hline \multirow[t]{2}{*}{ Cultural safety } & Class & 132 & 4.06 & 0.63 & \multirow[t]{2}{*}{0.086} \\
\hline & Clinic & 181 & 3.98 & 0.69 & \\
\hline
\end{tabular}

*indicates a significant value

Table 3 shows that the third-year students' classroom learning had a higher mean value than the fourth-year ones except for the domains of clinical safety, managing safety risk, and culture of safety. However, in classroom learning, the significant value was only in the domains of managing safety risk and culture of safety.

Table 3. The comparison of the scores in classroom learnings among student groups

\begin{tabular}{lccc}
\hline \multirow{2}{*}{ Patient safety Domain } & \multicolumn{3}{c}{ Classroom Learning } \\
\cline { 2 - 4 } & $3^{\text {rd }}$ year & $4^{\text {th }}$ year & t-test \\
\cline { 2 - 4 } & $M(S D)$ & $M(S D)$ & $p$ \\
\hline Clinical safety & $4.3(0.6)$ & $4.4(0.5)$ & 0.659 \\
Working in teams & $4.1(0.4)$ & $3.9(0.6)$ & 0.077 \\
Communicating & $4.3(0.5)$ & $4.2(0.5)$ & 0.070 \\
Managing safety risks & $4.0(0.6)$ & $4.2(0,5)$ & $0.004^{*}$ \\
Human and environmental & $4.1(0.5)$ & $4.0(0.7)$ & 0.118 \\
Adverse events & $4.1(0.5)$ & $4.0(0.6)$ & 0.102 \\
Cultural safety & $4.0(0.7)$ & $4.1(0.5)$ & $0.020^{*}$ \\
\hline
\end{tabular}

Table 4 shows the difference in clinical learning between each student group. The results showed that clinical students (professional program) had the highest mean values in all domains, followed by third and fourth-year students. The results of selfassessment in this clinical learning were found to be significant in all domains. 
Nurse Media Journal of Nursing, 10(1), 2020, 71

Table 4. The comparison of the scores in clinical learnings among student groups

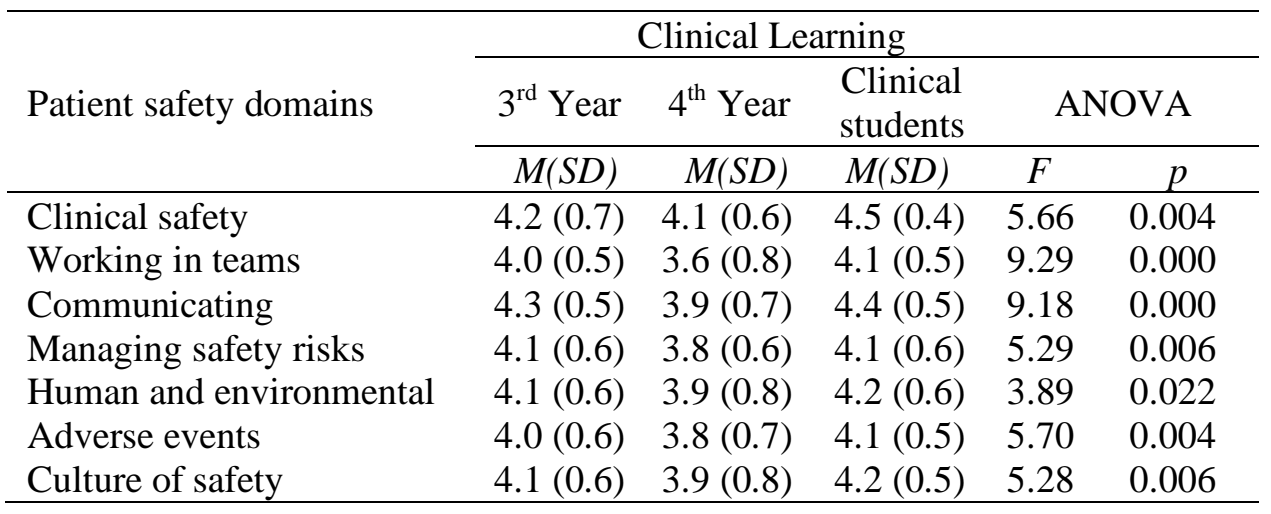

\section{DISCUSSION}

This study aimed to investigate the differences in patient safety competencies between classroom and clinical settings among nursing students. The results of self-assessment showed that differences between the classroom and clinical learning were evident. The clinical safety and effective communication dimensions were the two highest scores in the classroom-clinical learning. Meanwhile, dimensions of recognizing and responding to adverse events, working in teams, and cultural safety showed low self-perceptions.

Academic education is organized to provide theoretical and skill preparations, while clinical education helps students have direct experience to make decisions related to the actual condition of patients according to the knowledge that has been learned in class (Aktaş \& Karabulut, 2016). Previous studies have shown that if the quality of clinical learning increases, motivation in academic learning also increases (Aktaş \& Karabulut, 2016; Arkan, Ordin, \& Y1lmaz, 2018). The success of clinical learning is influenced by various factors such as individual factors, clinical instructors, academic instructors, and physical environment (Günay \& Kılınç, 2018). Personal experience is an individual factor that affects the success of clinical learning. What might have happened is a failure to connect the theoretical science taught in classroom learning to the clinical realm (Arkan et al., 2018). Students may receive broad theoretical knowledge from the school, but they cannot apply the knowledge obtained in actual practice (Günay \& Kılınç, 2018).

The study found that fourth-year students had lower self-ratings related to patient safety competencies than the third-year students in all dimensions of patient safety. These results indicated that lower year students have a higher rating than those students with a higher academic year. The same case is also found in some studies reporting that lower year students have higher self-assessment scores than the higher ones (Duhn, Karp, Oni, Edge, Ginsburg, \& VanDenKerkhof, 2012; Kajander-Unkuri et al., 2014). Such a situation may happen due to a lack of students' understanding related to patient safety, causing ignorance when there is something missing from the understanding and actions taken (Duhn et al., 2012; Ng et al., 2017; Sullivan, Hirst, \& Cronenwett, 2009). Gaps between academic and clinical knowledge also influence the way a person views patient safety issues (Usher et al., 2017). These theories explain why third-year students have 
better self-assessments since they have not gone through clinical experiences as much as fourth-year students.

This study also found that students had excellent results of self-assessment in the clinical safety domain both in the classroom or clinical learning. This domain is a nonsociocultural aspect that focuses on hand hygiene and infection control (Ginsburg, Tregunno, \& Norton, 2013). This result shows that students understand well every aspect of clinical safety that they have learned since the beginning of their study. Another reason is that this material is very popular in the health promotion programs that students present as counseling materials in the community (Duhn et al., 2012).

The results also showed that effective communication was highly rated in this study. This result is consistent with a previous study reporting that nursing students have a good assessment of effective communication skills (Duhn et al., 2012; Ginsburg et al., 2013). Students judged themselves to be able to carry out effective communication, especially to patients. Previous research stated that new nurses have confidence in their ability to communicate with doctors, patients, and families over time (between 6 - 12 months). In this study, students have previously gone through clinical practice for a cumulative duration of six months (Pfaff, Baxter, Jack, \& Ploeg, 2014).

Students showed a lack of self-assessment on recognizing and responding to adverse events, working in teams, and cultural safety. The domain of working in team focuses on managing inter-professional conflicts, power-sharing, and team dynamics (CPSI, 2009). This study showed similar results to previous research by Ginsburg, reporting that nurses have the lowest self-assessment in clinical settings compared to other health workers (pharmacy and doctor) (Ginsburg et al., 2013). One of the reasons causing a decrease in self-assessment in clinics is the low self-assessment of students in managing conflicts between professions. This conflict generally arises due to the paradigm of the dominance of the medical profession in health organizations (Sollami, Caricati, \& Mancini, 2018). However, this paradigm can be slowly reduced by the existence of interprofessional education programs that emphasize the alignment of the health profession in dealing with patients (Labrague, McEnroe - Petitte, Fronda, \& Obeidat, 2018; Sollami et al., 2018).

This study has limitations. Not all respondents in the study completed the questionnaire for both classroom and clinical assessment due to time constraints. Further research should consider longer period of time for data collection. A study about factors affecting self-assessment patient safety competence could be taken into account to help identify practical solutions to develop better learning programs/curricula.

\section{CONCLUSION}

This study revealed that the patient safety competencies of nursing students were higher in the classroom setting than that in the clinical setting. The patient safety competencies need to be improved in the education system through supervision and control. The curriculum needs to consider more learning on other aspects of patient safety, such as recognizing and responding unwanted events. Effective education and teaching should also be promoted to enhance higher inter-professional skills and communication skills 
among nursing students. Future studies may consider to investigate the factors that increase patient safety competence among nursing students in the clinical setting.

\section{ACKNOWLEDGMENT}

The researchers would like to thank the students for their participation in this study.

\section{CONFLICT OF INTEREST}

The authors declare no conflict of interest.

\section{REFERENCES}

Aktaş, Y. Y., \& Karabulut, N. (2016). A Survey on Turkish nursing students' perception of clinical learning environment and its association with academic motivation and clinical decision making. Nurse Education Today, 36, 124-128. doi:10.1016/j.nedt.2015.08.015

Arkan, B., Ordin, Y., \& Y1lmaz, D. (2018). Undergraduate nursing students' experience related to their clinical learning environment and factors affecting to their clinical learning process. Nurse Education in Practice, 29, 127-132. doi:10.1016/j.nepr.2017.12.005

Attree, M., Cooke, H., \& Wakefield, A. (2008). Patient safety in an English preregistration nursing curriculum. Nurse Education in Practice, 8(4), 239-248. doi:10.1016/j.nepr.2007.09.003

Colet, P., Cruz, J. C., Otaibi, J. Al, \& Qubeilat, H. (2015). Patient safety competence among nursing students in Shaqra University. Journal of Infection and Public Health, 8(4), 397-398. doi:10.1016/j.jiph.2015.04.007

CPSI. (2009). The Safety Competencies. Canadian Patient Safety Institute. doi: 10.1136/bmjqs-2011-000148. Retrieved from https://www.patientsafetyinstitute.ca/ en/toolsResources/safetyCompetencies/Documents/Safety\%20Competencies.pdf.

da Costa, T. D., Santos, V. E. P., Junior, M. A. F., Vitor, A. F., de Oliveira Salvador, P. T. C., \& Alves, K. Y. A. (2017). Evaluation procedures in health: Perspective of nursing care in patient safety. Applied Nursing Research, 35, 71-76. doi:10.1016/j.apnr.2017.02.015

Duhn, L., Karp, S., Oni, O., Edge, D., Ginsburg, L., \& VanDenKerkhof, E. (2012). Perspectives on Patient Safety Among Undergraduate Nursing Students. Journal of Nursing Education, 51(9), 526-531. doi:10.3928/01484834-20120706-04

Eva, K. W., \& Regehr, G. (2005). Self-Assessment in the Health Professions: A Reformulation and Research Agenda. Academic Medicine, 80(Supplement), S46S54. doi:10.1097/00001888-200510001-00015

Ginsburg, L., Castel, E., Tregunno, D., \& Norton, P. G. (2012). The H-PEPSS: An instrument to measure health professionals' perceptions of patient safety competence at entry into practice. BMJ Quality and Safety, 21(8), 676-684. doi:10.1136/bmjqs-2011-000601

Ginsburg, L. R., Tregunno, D., \& Norton, P. G. (2013). Self-reported patient safety competence among new graduates in medicine, nursing and pharmacy. BMJ Quality and Safety, 22(2), 147-154. doi:10.1136/bmjqs-2012-001308

Günay, U., \& Kılınç, G. (2018). The transfer of theoretical knowledge to clinical practice by nursing students and the difficulties they experience: A qualitative study. Nurse Education Today, 65, 81-86. doi:10.1016/j.nedt.2018.02.031 
Julianto, R., Thiangchanya, P., \& Boonyoung, N. (2014). Nurses' patient safety competencies in Aceh Province, Indonesia. Nurse Media Journal of Nursing, 4(1), 659-670.

Kajander-Unkuri, S., Meretoja, R., Katajisto, J., Saarikoski, M., Salminen, L., Suhonen, R., \& Leino-Kilpi, H. (2014). Self-assessed level of competence of graduating nursing students and factors related to it. Nurse Education Today, 34(5), 795-801. doi:10.1016/j.nedt.2013.08.009

Kim, C. H., Jeong, S. Y., \& Kwon, M. S. (2018). Effects of hazard perception training (HPT) on nursing students' risk sensitivity to patient safety and developing safety control confidence. Applied Nursing Research, 39, 160-166. doi:10.1016/j.apnr.2017.10.020

Labrague, L. J., McEnroe - Petitte, D. M., Fronda, D. C., \& Obeidat, A. A. (2018). Interprofessional simulation in undergraduate nursing program: An integrative review. Nurse Education Today, 67, 46-55. doi:10.1016/j.nedt.2018.05.001

Lukewich, J., Edge, D. S., Tranmer, J., Raymond, J., Miron, J., Ginsburg, L., \& van DenKerkhof, E. (2015). Undergraduate baccalaureate nursing students' selfreported confidence in learning about patient safety in the classroom and clinical settings: An annual cross-sectional study (2010-2013). International Journal of Nursing Studies, 52(5), 930-938. doi:10.1016/j.ijnurstu.2015.01.010

Mansour, M. (2015). Factor analysis of nursing students' perception of patient safety education. Nurse Education Today, 35(1), 32-37. doi:10.1016/j.nedt.2014.04.020

Mansour, M., Skull, A., \& Parker, M. (2015). Evaluation of World Health Organization Multi-Professional Patient Safety Curriculum Topics in Nursing Education: Pretest, post-test, none-experimental study. Journal of Professional Nursing, 31(5), 432-439. doi:10.1016/j.profnurs.2015.03.002

Ng, G. W. Y., Pun, J. K. H., So, E. H. K., Chiu, W. W. H., Leung, A. S. H., Stone, Y. H., ... \& Chan, E. A. (2017). Speak-up culture in an intensive care unit in Hong Kong: A cross-sectional survey exploring the communication openness perceptions of Chinese doctors and nurses. BMJ Open, 7(8), 1-12. doi:10.1136/bmjopen-2016015721

Pearson, P., \& Steven, A. (2009). Patient safety in health care professional educational curricula: examining the learning experience. Retrieved from http://www.birmingham.ac.uk/Documents/college-mds/haps/projects/ cfhep/psrp/ finalreports/PS030PSRPReportFINAL0609.pdf

Pfaff, K., Baxter, P., Jack, S., \& Ploeg, J. (2014). An integrative review of the factors influencing new graduate nurse engagement in interprofessional collaboration. Journal of Advanced Nursing, 70(1), 4-20. doi:10.1111/jan.12195

Sari D. (2015). Potret pelaksanaan patient safety mahasiswa profesi ners [The description of implementation patient safety by ners student]. Nurscope Jurnal Keperawatan dan Pemikiran Ilmiah, 1(5), 1-7.

Sollami, A., Caricati, L., \& Mancini, T. (2018). Does the readiness for interprofessional education reflect students' dominance orientation and professional commitment? Evidence from a sample of nursing students. Nurse Education Today, 68, 141-145. doi:10.1016/j.nedt.2018.06.009

Stan, C., \& Manea, A. D. (2015). The divergent relationship between assessment and self-assessment in higher education. experimental results. Procedia - Social and Behavioral Sciences, 209, 497-502. doi:10.1016/j.sbspro.2015.11.278 
Steven, A., Magnusson, C., Smith, P., \& Pearson, P. H. (2014). Patient safety in nursing education: Contexts, tensions and feeling safe to learn. Nurse Education Today, 34(2), 277-284. doi:10.1016/j.nedt.2013.04.025

Sullivan, D. T., Hirst, D., \& Cronenwett, L. (2009). Assessing quality and safety competencies of graduating prelicensure nursing students. Nursing Outlook, 57(6), 323-331. doi:10.1016/j.outlook.2009.08.004

Tella, S., Liukka, M., Jamookeeah, D., Smith, N.-J., Partanen, P., \& Turunen, H. (2013). What Do Nursing Students Learn About Patient Safety? An Integrative Literature Review. Journal of Nursing Education, 53(1), 7-13 doi:10.3928/01484834-20131209-04

The Joint Commission. (2018). National patient safety golas effective january 2020: Hospiral accreditation program. Retrieved from https://www.jointcommission.org/ standards/national-patient-safety-goals/hospital-2020-national-patient-safety-goals/

Usher, K., Woods, C., Conway, J., Lea, J., Parker, V., Barrett, F., .. \& \& Jackson, D. (2018). Patient safety content and delivery in pre-registration nursing curricula: A national cross-sectional survey study. Nurse Education Today, 66, 82-89. doi:10.1016/j.nedt.2018.04.013

Usher, K., Woods, C., Parmenter, G., Hutchinson, M., Mannix, J., Power, T., ... \& Jackson, D. (2017). Self-reported confidence in patient safety knowledge among Australian undergraduate nursing students: A multi-site cross-sectional survey study. International Journal of Nursing Studies, 71, 89-96. doi:10.1016/j.ijnurstu.2017.03.006

Wolff, M., Santen, S. A., Hopson, L. R., Hemphill, R. R., \& Farrell, S. E. (2017). What's the evidence: Self-assessment implications for life-long learning in emergency medicine. Journal of Emergency Medicine, 53(1), 116-120. doi:10.1016/j.jemermed.2017.02.004

World Health Organization. (2011). Patient safety curriculum guide: Multi-professional edition. Malta: WHO Press. Retrieved from https://apps.who.int/iris/bitstream/ handle/10665/44641/9789241501958_eng.pdf;jsessionid=0E4880DD08D36F97FA D83204B444E3D4? sequence $=1$ 